\title{
Risk Factors Associated with Invasive Pulmonary Mycosis Among Severe Influenza Patients in Beijing City, China
}

\section{Maoqing Guo \\ Zhaohui Tong}

Department of Respiratory and Critical Care Medicine, Beijing Institute of Respiratory Medicine, Beijing Chao-Yang Hospital, Capital Medical University, Beijing, 100020, People's Republic of China
Correspondence: Zhaohui Tong Department of Respiratory and Critical Care Medicine, Beijing Chao-Yang Hospital, Capital Medical University, Beijing, 100020, People's Republic of China

Email tongzhaohuicy@sina.com
Objective: Influenza co-infection with fungal infection increases the risk of death. Our study was to estimate risk factors associated with invasive pulmonary mycosis (IPM) among severe influenza patients at a single center in Beijing, China.

Methods: A retrospective chart review was carried out of all patients with severe influenza admitted to respiratory the department including the respiratory intensive care unit (RICU) during the 2014 to 2019 influenza seasons in Beijing Chao-yang hospital, China. We compared the differences of characteristics and examination outcomes between IPM patients and non-IPM patients, and explored the predictors of IPM by a multivariate logistic regression.

Results: Influenza associated IPM was found in 65 of 131 (49.62\%) patients. The average age of IPM patients was $57.28 \pm 14.56$ years and $70.77 \%$ were male. The mortality rate was much higher in the IPM group than the non-IPM group (34.85\% versus $18.46 \%, P=0.026$ ). Older age, hypoimmunity, liver disease, hypertension, positive serum GM test, steroids using, gasping, gastrointestinal symptoms, high APECHEII, low oxygenation index, other viruses co-infection, bacterial co-infection, low lymphocyte counts, low CD4+ T-cell counts, low CD8+ T-cell counts, low RBC, low hemoglobin, low platelets, high $\mathrm{N} \%$, low total protein, high CRP, low albumin, low fibrinogen, high BUN, positive serum GM test, more mechanical ventilation requirement, and more renal replacement requirement were risk factors of influenza IPM co-infection.

Conclusion: IPM is a severe complication of influenza hospitalizations. It is associated with increasing mortality, longer hospital stays, and higher hospital charges compared with nonIPM patients. Clinicians caring for patients with severe influenza should consider IPM.

Keywords: influenza, invasive pulmonary mycosis, infection, hospitalization, incidence rate

\section{Introduction}

Influenza is an heterogeneous disease which can cause 3-5 million severe cases and 250,000-500,000 deaths every year. ${ }^{1}$ Its severity varies widely because of patients, different ages, complications, mortality, onset season, duration, and response to drugs, so the pathogenesis and prognosis of each influenza patient is different. ${ }^{2}$

In our clinical work, we find severe influenza patients are often complicated with bacterial and/or fungal infection, which greatly increases the mortality rate of patients, prolongs the time of hospitalization, and increases the personal and social economic burden. ${ }^{3,4}$

Invasive pulmonary mycosis (IPM) is a well-recognized disease occurring in immunocompromised patients. In recent years, influenza has been confirmed as 
a risk factor for IPM, because influenza can inhibit the immune system of patients, creating an ideal environment for the occurrence of bacterial and fungal infections. ${ }^{5}$ Influenza associated IPM increases the difficulty of treatment and the risk of death in patients. Shu et $\mathrm{al}^{6}$ pointed out the mortality rate of IPM influenza co-infection is about $50-60 \%$, which is 5-times higher than that among patients with influenza infection alone.

From the first article published in 1952 about influenza co-infected with aspergillus to now, ${ }^{7}$ almost all research about influenza associated fungal infection focused on aspergillus, and most relevant research reports appeared in the form of case reports and small case series. ${ }^{8-11}$ There is no research focus on other types of fungal co-infection and no systemic research to investigate the characteristics of fungus influenza co-infections.

Our study aimed to analyze all important information of severe influenza patients who were admitted to Beijing Chao-yang Hospital during the 2014 to 2019 influenza season, and explore potential risk factors of influenza IPM co-infection.

\section{Materials and Methods}

\section{Study Population and Groups}

\section{Cases Selection}

All hospitalized patients who were confirmed with severe influenza in the respiratory department including the RICU of Beijing Chao-Yang Hospital during January 2014 to March 2019 were our subjects. We collected the main data from the electronic medical record system for daily work.

\section{Group Division}

All selected influenza patients were divided into two groups: IPM group and non-IPM group. The patients in the IPM group were infected with proven or probable IPM, and patients in the non-IPM group were without evidence of fungal infection while hospitalized. Cases involving nonspecific viral infections or without confirmatory influenza testing, insufficient patient information, possible invasive pulmonary fungal infection, or fungal colonization were excluded.

\section{Definitions}

\section{Definition of Influenza}

Diagnosis of influenza virus infection was based on a positive result from a probe-based reverse-transcriptase polymerase chain reaction (RT-PCR) test for influenza from lower respiratory tract specimens or nasopharyngeal swab. ${ }^{8,9}$

\section{Definition of Severe Influenza}

Patients needed to meet one or more of the following clinical features: (1) Persistent fever $>3$ days, accompanied by severe cough, expectoration of purulent sputum, blood sputum, or chest pain; (2) Fast breathing rate (>30 times/ min), dyspnea, and cyanosis of lips; (3) Altered mental status: slow reaction, drowsiness, restlessness, convulsion, etc; (4) Severe vomiting and diarrhea with dehydration; (5) Pneumonia; and (6) Underlying diseases were significantly aggravated, with organ dysfunction or failure. These diagnostic criteria come from the 2018 influenza treatment program of China.

\section{Definition of IPM}

Patients had proven IPM if there was microscopic evidence of dichotomous branching hyphae with a positive culture for fungus spp through an endobronchial biopsy, irrespective of host factors or clinical features. ${ }^{12,13}$ Probable IPM requires a host factor, clinical features, and mycological evidence of fungus (positive smear or/and culture of sputum or bronchoalveolar lavage fluid). ${ }^{14-16}$

\section{Data Collection and Analysis}

We collected the main data of selected patients from the electronic medical record system in our hospital, including demographics, underlying diseases, and the use of immunosuppressive agents and steroids longer than 7 days before or after admission and main examinations, data, complications, needs for organ support, lengths of total hospitalization days, and mortality. ${ }^{13}$ Our collected examination data included laboratory examinations and radiological examinations. Laboratory examinations included the influenza type, white blood count (WBC), and lymphocyte and CD4+ $\mathrm{T}$ lymphocyte counts, fasting blood glucose (FBG), myocardial enzymes, main data of liver function and kidney function, and airway secretions culture during hospitalizations. Radiological examinations mainly included chest CT images. For those with IPM, data on the number of days between the diagnoses of influenza and IPM, the fungus species from lower respiratory tract (LRT) cultures, serum and/or bronchoalveolar lavage fluid (BALF), galactomannan (GM) and 1-3- $\beta$-D-glucan test $(\mathrm{G})$ levels, and antifungal therapy information were also collected. We first described the overview of this influenza pandemic (from January 2014 to March 2019) and fungus co-infection. Then we compared all collected 
data between two groups. At last, we performed a logistic regression analysis to explore the condition's risk factors of IPM in influenza patients.

\section{Statistical Analysis}

All data were analyzed with SPSS 22.0 software. Quantitative data was expressed as $\overline{\mathrm{x}} \pm \mathrm{SD}$ and were compared using $t$-tests when distributed normally. Nonnormally distributed quantitative data was expressed as medians and quartiles, and we compared the difference by using Wilcoxon rank-sum tests. $\chi^{2}$ tests was used to compare the difference of categorical data. In order to identify independent risk factors for influenza co-infected with IPM, we used a multivariate logistic regression to analyze variables with a $P$-value less than 0.2 .

\section{Results}

\section{Characteristics of Patients}

In our study, a total of 131 influenza patients in the respiratory department (including RICU) at Beijing Chaoyang Hospital due to respiratory failure from January 2014 to March 2019 met our requirements. The mortality rate was $26.72 \%$ (35 cases). The incidence of IPM influenza co-infection was $49.62 \%$ (65 cases); two patient were diagnosed by histopathology, 63 patients were diagnosed as probable fungal infection, the mean age of IPM patients was $57.28 \pm 14.56$ years, $70.77 \%$ were male, the mean time from influenza diagnosis to IPM diagnosis was $15.62 \pm 8.86$ days, and the mortality rate of the IPM group was $35.38 \%$ versus $18.18 \%$ in the non-IPM group. In IPM cases, cardiovascular diseases (heart disease or hypertension) (47, $71.21 \%$ ), diabetes mellitus (DM) (16, 24.24\%), and chronic pulmonary disease $(15,23.08 \%)$ were the top three comorbidities, and $70.77 \%$ of patients in the IPM group had immune deficiency (Tables 1 and 2).

\section{Comparisons of Two Groups}

\section{General Information}

The incidence of IPM influenza co-infection in our study was $49.62 \%$. Among all these IPM patients, the number with candida co-infection was $55(84.62 \%)$, aspergillus coinfection was $23(35.38 \%)$, sporozoan co-infection was four $(6.15 \%)$, and many patients suffered two or more kinds of fungus.

There were more patients with immunodeficiency on admission in the IPM group than non-IPM group (70.77\% versus $51.52 \%, P=0.024)$. Immunodeficiency in our study
Table I Demographics of Patients Diagnosed with Severe Influenza $(\mathrm{N}=|3|)$

\begin{tabular}{|c|c|c|c|}
\hline & $\begin{array}{l}\text { Non-IPM } \\
(n=66)\end{array}$ & $\begin{array}{l}\text { IPM } \\
(n=65)\end{array}$ & $P$-value \\
\hline Age, years & $52.97 \pm 14.34$ & $57.28 \pm 14.56$ & 0.09 \\
\hline Gender & & & 0.295 \\
\hline Male, $n$ & 41 & 46 & \\
\hline Female, $n$ & 25 & 19 & \\
\hline $\begin{array}{l}\text { Underlying lung disease, } \\
\mathrm{n}\end{array}$ & 12 & 15 & 0.546 \\
\hline Chronic heart disease, $\mathrm{n}$ & 8 & 12 & 0.350 \\
\hline Hypertension, $n$ & 27 & 35 & 0.188 \\
\hline Digestive disorders, $\mathrm{n}$ & 1 & I & 0.991 \\
\hline Diabetes, $\mathrm{n}$ & 11 & 16 & 0.3 \\
\hline Liver disease, $\mathrm{n}$ & 1 & 4 & 0.166 \\
\hline Tumor, $\mathrm{n}$ & 0 & 4 & 0.044 \\
\hline $\begin{array}{l}\text { Cerebrovascular } \\
\text { disease, } \mathrm{n}\end{array}$ & 1 & 2 & 0.568 \\
\hline $\begin{array}{l}\text { Connective tissue } \\
\text { disease, } n\end{array}$ & 2 & 3 & 0.507 \\
\hline Hyperthyreosis, $n$ & 0 & I & 0.319 \\
\hline Pregnancy, n & 0 & 2 & 0.157 \\
\hline $\begin{array}{l}\text { Connective tissue } \\
\text { disorders, } \mathrm{n}\end{array}$ & 2 & 3 & 0.661 \\
\hline Transplantation, $\mathrm{n}$ & 3 & 3 & 0.985 \\
\hline Renal failure, $n$ & 0 & 4 & 0.044 \\
\hline Benign hematopathy, $\mathrm{n}$ & 1 & 2 & 0.568 \\
\hline HIV, n & 0 & 1 & 0.319 \\
\hline BMI $(\geq 28), n$ & 15 & 9 & 0.189 \\
\hline Steroid use, $n$ & 17 & 26 & 0.083 \\
\hline Hypoimmunity, n & 34 & 46 & 0.024 \\
\hline
\end{tabular}

mainly referred to age $>65$ years, immunosuppressant use, steroid use, connective tissue disease, diabetes, renal failure, liver disease, COPD, HIV, malignant tumor, and organ transplantations. When we compared age, immunosuppressant use, steroid use, connective tissue disease, diabetes, renal failure, liver disease, COPD, HIV, malignant tumor, and organ transplantations as independent variables, other variables have no statistical difference except tumor and renal failure between two groups. In addition, the differences in gender, heart disease, obesity, chronic heart failure, digestive diseases, hypertension, cerebrovascular disease, hyperthyreosis, pregnancy, and benign hematopathy between two groups were not statistically significant. There were nine patients in the IPM group and 15 patients in the non-IPM group when body mass index (BMI) was bigger than 28 was selected as the cut-off point (the difference of BMI is also not statistically significant, $P=0.189$ ). 
Table 2 Symptoms, Admission Assessment, Pathogens, and Outcomes of Patients

\begin{tabular}{|c|c|c|c|}
\hline & Non-IPM (66) & IPM (65) & $P$-value \\
\hline Fever, $\mathrm{n}$ & 62 & 62 & 0.713 \\
\hline Breathlessness, $n$ & 46 & 55 & 0.042 \\
\hline Cough, $n$ & 63 & 60 & 0.546 \\
\hline Sputum, n & 62 & 60 & 0.712 \\
\hline Hemoptysis, $n$ & 3 & I & 0.317 \\
\hline Debilitation, $n$ & 2 & 2 & 0.988 \\
\hline Chest pain, $n$ & I & 0 & 0.319 \\
\hline Gastrointestinal symptom, $\mathrm{n}$ & 3 & 7 & 0.18 \\
\hline Headache, $n$ & 4 & 3 & 0.713 \\
\hline Pharyngeal abnormalities, $n$ & 2 & I & 0.568 \\
\hline Nasal discomfort, $\mathrm{n}$ & 2 & I & 0.568 \\
\hline Other viruses co-infection, $\mathrm{n}$ & 18 & 30 & 0.033 \\
\hline Mycoplasma co-infection, $n$ & 5 & I & 0.091 \\
\hline Highest heart rate, times/min & $102.91 \pm 19.72$ & $103.32 \pm 16.16$ & 0.896 \\
\hline Respiratory frequency, times/min & $27.73 \pm 7.67$ & $29.43 \pm 8.58$ & 0.233 \\
\hline Urine volume during the first 24 hours of admission, $\mathrm{mL}$ & $\mathrm{I}, 765.50 \pm 841.35$ & $1,700.74 \pm 887.10$ & 0.699 \\
\hline APECHEII score & $8.85 \pm 6.34$ & $11.94 \pm 6.50$ & 0.007 \\
\hline SOFA score & $4.59 \pm 3.56$ & $4.82 \pm 2.49$ & 0.677 \\
\hline SIRS score & $3.83 \pm 1.83$ & $4.29 \pm 1.55$ & 0.124 \\
\hline Blood $\mathrm{PH}$ & $7.4 I \pm .073$ & $7.4 I \pm .085$ & 0.952 \\
\hline Arterial $\mathrm{pO}_{2}$ on admission & $76.45 \pm 23.03$ & $72.70 \pm 22.82$ & 0.352 \\
\hline Arterial $\mathrm{pCO}_{2}$ on admission & $37.91 \pm 9.90$ & $37.75 \pm 12.00$ & 0.933 \\
\hline Oxygenation index & $192.10 \pm 114.70$ & $|66.1| \pm 97.72$ & 0.165 \\
\hline Chest radiograph score & $3.4 I \pm 0.9 I$ & $3.57 \pm 0.83$ & 0.295 \\
\hline Interval between onset and antiviral treatment, days & $8.38 \pm 8.36$ & $9.29 \pm 7.09$ & 0.501 \\
\hline Treatment time before admission, days & $11.62 \pm 11.09$ & $11.40 \pm 8.07$ & 0.896 \\
\hline Length of hospitalization, days & $17.36 \pm 12.56$ & $26.79 \pm 26.73$ & 0.011 \\
\hline Mortality, n & 12 & 23 & 0.026 \\
\hline
\end{tabular}

Compared with the non-IPM group, the patients in the IPM group were in more serious conditions (Acute Physiology, Age, Chronic Health Evaluation II, APECHE II score was $11.94 \pm 6.50$ points versus $8.85 \pm 6.34$, $P=0.007$ ). The mean length of total hospital stay was $26.79 \pm 26.73$ days in the IPM group versus $17.36 \pm 12.56$ days in the non-IPM group $(P=0.011)$. Fever $(62,95.4 \%)$, cough $(60,92.3 \%)$, sputum production $(62,95.4 \%)$, and breathlessness $(55,84.6 \%)$ were the major presenting symptoms. IPM patients needed more time to recover than non-IPM patients. Twenty-three IPM patients died and 12 non-IPM patients died. The mortality rate in the IPM group was much higher than the non-IPM group (34.85\% versus $18.46 \%, P=0.026$ ) (Tables 1 and 2 ).

\section{Examinations Outcomes}

Lymphocyte count in the IPM group was lower than the non-IPM group $\left[(0.82 \pm 0.59) * 10^{\wedge} 9 / \mathrm{L}\right.$ versus $(1.09 \pm 0.74)$ $\left.* 10^{\wedge} 9 / \mathrm{L}, P=0.023\right]$, especially CD4+ T cells $(P<0.001)$ and CD8+ T cells $(P=0.003)$. So was $\mathrm{RBC}\left[(3.94 \pm 1.00)^{*} 10^{\wedge} 9 / \mathrm{L}\right.$ versus $\left.(4.28 \pm 0.69)^{*} 10^{\wedge} 9 / \mathrm{L}, P=0.023\right]$, hemoglobin (120.11 \pm 25.35 versus $133.41 \pm 40.87, P=0.027$ ), platelets (155.14 $\pm 78.29 * 10^{\wedge} 9 / \mathrm{L}$ vs $\left.191.39 \pm 109.60^{*} 10^{\wedge} 9 / \mathrm{L}, P=0.031\right), \mathrm{N} \%$ (80.79 \pm 11.96 versus $73.77 \pm 19.56, P=0.015)$, and albumin (30.53 \pm 4.359 versus $32.89 \pm 5.134, P=0.005$ ). There was no statistically significant difference in WBC, absolute neutrophil counts, C-reactive protein (CRP), procalcitonin (PCT), erythrocyte sedimentation rate (ESR), d-dimer levels, clotting time, fibrinogen, creatine kinase (CK), creatine kinasemyocardial isoenzyme (CK-MB), creatinine, blood urea nitrogenurea (BUN), indirect bilirubin, direct bilirubin, total protein, influenza type, and FBG of the first day after admission between two groups. The patients co-infected with bacterial and other kinds of viruses were more likely to suffer IPM $(P<0.05)$. The consolidation was seen more often than ground-glass attenuation in the CT imaging of IPM patients, but there was no statistically significant difference $(P=0.537)$. The incidence of pleural effusion was similar between the two groups (Table 3 ). 
Table 3 Laboratory Examinations and Radiological Findings Between the Two Groups

\begin{tabular}{|c|c|c|c|}
\hline & Non-IPM $(n=66)$ & IPM $(n=65)$ & $P$-value \\
\hline WBC, $* 10^{\wedge} 9 / \mathrm{L}$ & $7.73 \pm 5.07$ & $7.37 \pm 3.86$ & 0.643 \\
\hline Neutrophils, $* 10^{\wedge} 9 / \mathrm{L}$ & $7.85 \pm 10.72$ & $6.13 \pm 3.68$ & 0.224 \\
\hline N\% & $73.77 \pm 19.56$ & $80.79 \pm 11.96$ & 0.015 \\
\hline Lymphocyte, *10^9/L & $1.09 \pm 0.74$ & $0.82 \pm 0.59$ & 0.023 \\
\hline$L \%$ & $17.01 \pm 11.68$ & $13.30 \pm 8.53$ & 0.04 \\
\hline RBC, $* 10^{\wedge} \mid 2 / L$ & $4.28 \pm 0.69$ & $3.94 \pm 1.00$ & 0.023 \\
\hline Hemoglobin, $\mathrm{g} / \mathrm{mL}$ & $|33.4| \pm 40.87$ & $|20.1| \pm 25.36$ & 0.027 \\
\hline Platelets, $* 10^{\wedge 9 / L}$ & $191.39 \pm 109.60$ & $|55| 4 \pm 78.29$. & 0.031 \\
\hline CRP, mg/L & $9.70 \pm 7.54$ & $12.58 \pm 12.43$ & 0.111 \\
\hline $\mathrm{ESR}, \mathrm{mm} / \mathrm{h}$ & $23.69 \pm 18.85$ & $26.23 \pm 20.48$ & 0.462 \\
\hline $\mathrm{PCT}, \mathrm{ng} / \mathrm{mL}$ & $9.3 \pm 31.40$ & $8.09 \pm 32.73$ & 0.83 \\
\hline BUN, $\mathrm{mmol} / \mathrm{L}$ & $6.95 \pm 4.78$ & $8.33 \pm 5.68$ & 0.133 \\
\hline Creatinine, $\mu \mathrm{mol} / \mathrm{L}$ & $90.59 \pm 76.81$ & $105.31 \pm 109.67$ & 0.375 \\
\hline Fasting blood glucose on admission, $\mathrm{mmol} / \mathrm{L}$ & $8.57 \pm 5.40$ & $7.93 \pm 3.51$ & 0.42 \\
\hline $\mathrm{ALT}, \mathrm{U} / \mathrm{L}$ & $46.59 \pm 52.53$ & $52.03 \pm 57.14$ & 0.572 \\
\hline AST, U/L & $100.61 \pm 231.90$ & $95.05 \pm 136.55$ & 0.868 \\
\hline Albumin, $g / L$ & $32.89 \pm 5.13$ & $30.53 \pm 4.36$ & 0.005 \\
\hline Total protein, $\mathrm{g} / \mathrm{L}$ & $60.48 \pm 8.36$ & $57.94 \pm 9.83$ & 0.112 \\
\hline Direct Bilirubin, umol/L & $10.29 \pm 17.60$ & $7.44 \pm 6.87$ & 0.224 \\
\hline Indirect bilirubin, umol/L & $6.67 \pm 3.39$ & $9.14 \pm 22.97$ & 0.39 \\
\hline CK, U/L & $284.77 \pm 625.90$ & $350.78 \pm 511.13$ & 0.51 \\
\hline CK-MB, ng/mL & $1.95 \pm 4.009$ & $1.98 \pm 3.306$ & 0.964 \\
\hline $\mathrm{LDH}, \mathrm{U} / \mathrm{L}$ & $575.53 \pm 527.71$ & $608.72 \pm 406.60$ & 0.688 \\
\hline D-dimer, mg/L & $7.01 \pm 10.34$ & $17.04 \pm 87.72$ & 0.358 \\
\hline $\mathrm{TT}, \mathrm{S}$ & $19.67 \pm 5.16$ & $19.55 \pm 2.79$ & 0.87 \\
\hline APTT, S & $32.39 \pm 10.63$ & $32.16 \pm 9.37$ & 0.896 \\
\hline PT, S & $13.24 \pm 4.35$ & $13.85 \pm 9.30$ & 0.631 \\
\hline Fibrinogen, $\mathrm{mg} / \mathrm{L}$ & $424.24 \pm 190.70$ & $385.96 \pm|4| .97$ & 0.195 \\
\hline CD4+ T cell, cell $/ \mu \mathrm{L}$ & $398.92 \pm 271.75$ & $238.54 \pm 149.27$ & 0 \\
\hline CD8+ T cell, cell/ $\mu \mathrm{L}$ & $217.11 \pm 165.50$ & $|47.45 \pm 85.9|$ & 0.003 \\
\hline CD4+ $T$ cell $/ C D 8+T$ cell & $2.24 \pm 1.30$ & $1.86 \pm 1.07$ & 0.073 \\
\hline Pleural effusion, $n$ & 33 & 39 & 0.25 \\
\hline
\end{tabular}


Table 3 (Continued).

\begin{tabular}{|l|l|l|l|}
\hline & Non-IPM (n=66) & IPM (n=65) & P-value \\
\hline $\begin{array}{l}\text { Imaging } \\
\text { Ground-glass attenuation, } \mathrm{n} \\
\text { Consolidation, } \mathrm{n}\end{array}$ & 33 & 26 & 0.537 \\
\hline G test, $\mathrm{n}$ & 33 & 39 & 15 \\
\hline GM test, $\mathrm{n}$ & 14 & 21 & 0.87 \\
\hline Complicated arrhythmia, $\mathrm{n}$ & 13 & 7 & 0.123 \\
\hline Bacterial co-infection, $\mathrm{n}$ & 8 & 30 & 0.808 \\
\hline Steroid use after admission, $\mathrm{n}$ & 15 & 18 & 0.007 \\
\hline Antibiotic combination, $\mathrm{n}$ & 25 & 53 & 0.153 \\
\hline Influenza virus type & 50 & & 0.637 \\
\hline Influenza A, $\mathrm{n}$ & & 59 & 0.545 \\
\hline Influenza B, $\mathrm{n}$ & 56 & 6 & 3 \\
\hline Influenza A \pm B, $\mathrm{n}$ & 3 & 4 & \\
\hline
\end{tabular}

\section{Organ Support Comparison}

The needing of extracorporeal membrane oxygenation (ECMO) support in two groups did not differ significantly $(P=0.517)$. More patients in the IPM group needed mechanical ventilation (including IPPV and non-invasive ventilation) $(71.21 \%$ versus $55.38 \%, P=0.035)$ and renal replacement therapies $(19.70 \%$ versus $6.15 \%, P=0.018)$ compared with the non-IPM group, but there was no difference in use of non-invasive ventilation and invasive positive pressure ventilation (IPPV) $(P=0.731)$, and the application time of mechanical ventilation and renal replacement therapies was not significantly different either (Table 4).

Table 4 Organ Support Needs and Complications Between the Two Groups

\begin{tabular}{|l|l|l|l|}
\hline & $\begin{array}{l}\text { Non-IPM } \\
(\mathbf{n}=66)\end{array}$ & $\begin{array}{l}\text { IPM } \\
(\mathbf{n}=65)\end{array}$ & P-value \\
\hline ECMO, $\mathrm{n}$ & 10 & 13 & 0.517 \\
ECMO days & $16.7 \pm 13.23$ & $20.85 \pm 14.72$ & 0.492 \\
Mechanical ventilation, $\mathrm{n}$ & 36 & 47 & 0.035 \\
Non-invasive ventilation, $\mathrm{n}$ & 8 & 9 & 0.731 \\
IPPV, $\mathrm{n}$ & 28 & 38 & \\
Mechanical ventilation days & $24.97 \pm 13.29$ & $28.21 \pm 16.38$ & 0.336 \\
Renal replacement therapy, $\mathrm{n}$ & 4 & 13 & 0.018 \\
Renal replacement therapy & $20.75 \pm 9.74$ & $23.54 \pm 11.68$ & 0.673 \\
days & & & \\
\hline
\end{tabular}

\section{Risk Factors for Influenza Co-Infection with IPM (Table 5)}

We performed a multivariate logistic-regression analysis to investigate risk factors of IPM in influenza patients. In our study we found that older age, hypoimmunity, liver disease, hypertension, positive serum GM test, steroids using, gasping, gastrointestinal symptoms, high APECHEII, low oxygenation index, other viruses co-infection, bacterial coinfection, low lymphocyte counts, low $\mathrm{CD} 4+\mathrm{T}$ cell counts, low CD8+ T cell counts, low RBC, low hemoglobin, low platelets, high N\%, low total protein, high CRP, low albumin, low fibrinogen, high BUN, positive serum GM test, more mechanical ventilation requirement, and more renal replacement requirement were independent risk factors of influenza virus infection combined with IPM, as shown in Table 5.

\section{Discussion}

After the 2009 H1N1 influenza pandemic outbreak, there were more and more studies describing influenza co-infection. However, almost all reports focused on bacteria and aspergillus co-infection and there was no study to report other kinds of fungus coinfection. ${ }^{10,11,17-22}$ Our study may be the first to systematically and comprehensively summarize the clinical characteristics of influenza co-infected with IPM. Based on the sample size of cases and complete data, 
Table 5 Binary Logistic-Regression Analysis for Risk Factors and Predictors of Prognosis for IPM in Patients with Influenza

\begin{tabular}{|c|c|c|c|c|c|}
\hline & \multirow[t]{2}{*}{ Wald } & \multirow[t]{2}{*}{$P$-value } & \multirow[t]{2}{*}{ Odds Ratio } & \multicolumn{2}{|c|}{ 95\% Confidence Interval } \\
\hline & & & & Inferior & Superior \\
\hline Age & $|19.14|$ & $<0.001$ & 1.039 & 1.032 & 1.047 \\
\hline Hypoimmunity & 7.651 & 0.006 & 0.766 & 0.634 & 0.925 \\
\hline Liver disease & 51.767 & $<0.001$ & 4.225 & 2.853 & 6.256 \\
\hline Hypertension & 22.505 & $<0.001$ & 0.687 & 0.588 & 0.802 \\
\hline Steroids using & 19.943 & $<0.001$ & 0.68 & 0.574 & 0.806 \\
\hline Gasping & 25.154 & $<0.001$ & 0.607 & 0.5 & 0.738 \\
\hline Gastrointestinal symptoms & 89.437 & $<0.001$ & 0.275 & 0.211 & 0.36 \\
\hline APECHE II & 88.015 & $<0.001$ & 1.078 & 1.061 & 1.095 \\
\hline Oxygenation index & 221.44 & $<0.001$ & 1.009 & 1.008 & 1.011 \\
\hline N\% & 61.657 & $<0.001$ & 1.029 & 1.021 & 1.036 \\
\hline Lymphocyte counts & 94.636 & $<0.001$ & 2.458 & 2.051 & 2.946 \\
\hline L\% & 6.177 & 0.013 & 1.016 & 1.003 & 1.029 \\
\hline RBC & 14.007 & $<0.001$ & 1.293 & 1.13 & 1.479 \\
\hline Hemoglobin & 104.978 & $<0.001$ & 0.981 & 0.978 & 0.985 \\
\hline Platelets & 12.083 & 0.001 & 1.002 & 1.001 & 1.003 \\
\hline CRP & 68.31 & $<0.001$ & 1.05 & 1.038 & 1.062 \\
\hline Blood urea nitrogen & 251.046 & $<0.001$ & 0.846 & 0.829 & 0.864 \\
\hline Albumin & $14 \mid .887$ & $<0.001$ & 0.879 & 0.86 & 0.898 \\
\hline Total protein & 37.787 & $<0.001$ & 1.042 & 1.028 & 1.055 \\
\hline Fibrinogen & 12.96 & $<0.001$ & 1.001 & I & 1.001 \\
\hline CD4+ $\mathrm{T}$ cell counts & 54.81 & $<0.001$ & 0.997 & 0.996 & 0.998 \\
\hline $\mathrm{CD} 8+\mathrm{T}$ cell counts & 88.208 & $<0.001$ & 0.994 & 0.993 & 0.995 \\
\hline CD4+ $T$ cell counts $/ C D 8+T$ cell counts & 30.601 & $<0.001$ & 0.741 & 0.666 & 0.824 \\
\hline GM test & 26.96 & $<0.001$ & 0.648 & 0.551 & 0.764 \\
\hline Bacterial co-infection & 232.467 & $<0.001$ & 0.224 & 0.184 & 0.271 \\
\hline Other viruses co-infection & 53.362 & $<0.001$ & 0.553 & $0.47 I$ & 0.648 \\
\hline Mechanical ventilation & 16.348 & $<0.001$ & 0.619 & 0.491 & 0.781 \\
\hline Renal replacement therapy & 60.681 & $<0.001$ & 0.333 & 0.253 & 0.439 \\
\hline
\end{tabular}

we think our study is very valuable for clinical diagnosis and medication guidance.

The incidence of IPM influenza co-infection in our study was about $49.62 \%$; therefore, we speculate the incidence of IPM influenza co-infection in critically ill patients in northern China is also about 50\%. Among all these IPM patients, we found three kinds of fungus: candida was the most common $(84.62 \%)$, aspergillus was the second $(35.38 \%)$, the third was sporozoan $(6.15 \%)$. Compared with non-IPM patients, IPM patients needed longer hospital stay, more substantial consumption of health care resources, and had higher in-hospital mortality.

In our study, we found the most common presenting clinical features of IPM were fever, dyspnea, and cough, which is in agreement with prior studies, ${ }^{9,21,23-25}$ but these symptoms also happened in non-IPM patients, so we think they have no diagnostic value. In radiological images, we mainly compared the difference of consolidation and ground-glass opacities by HRCT, consolidation was seen more often than ground-glass opacities in the CT imaging of IPM patients, but there was no statistical difference in the two groups as a result. The $\mathrm{CT}$ images of invasive pulmonary aspergillosis and candidiasis were similar. Consolidation is the most common feature of the two diseases, randomly distributed consolidation is more likely in candidiasis, while centrilobular nodules and consolidation suggest invasive pulmonary aspergillosis. Previous studies have pointed out that CT halo sign and vacuole are not helpful in distinguishing different fungal diseases, ${ }^{26}$ so we didn't assess these two features.

In recent years, the incidence rate of IPM has increased year by year with the aging of the social population, the wide application of hormones, immunosuppressants, cytotoxic drugs, chemoradiotherapy, and the variety of broad-spectrum antibiotics. Candida and Aspergillus are 
the two most common pathogens. Pulmonary candidiasis usually infects critically ill patients with hypoimmunity, especially those with indwelling catheters, using broadspectrum antibiotics and diabetes. ${ }^{26,27}$ Aspergillus infection accounted for $60 \%$ of IPM, especially in patients with acute leukemia and accepting hematopoietic stem cell transplantation, ${ }^{27,28}$ and long-term using of steroids and solid organ transplantation also increase the risk of invasive pulmonary aspergillosis. ${ }^{26,29}$ Previous studies have confirmed that bacterial co-infection is the first cause of death in influenza patients, ${ }^{7,16}$ so the application of powerful broad-spectrum antibiotics is common in severe influenza patients, maybe this is the reason for high incidence of candida infection in our study.

As we know, immunocompromised hosts were more likely to get fungal infection. In our study, we found IPM co-infection with influenza not only happened in immunocompromised hosts but also happened in immunecompetent hosts, consistent with previous reports. ${ }^{9,21}$ When we compared age, steroid use, liver disease, diabetes, connective tissue disease, underlying lung disease, transplantation, and HIV as a single variable, there was no statistical difference between IPM and non-IPM, the reason for this result may be that the sample size is too small. Therefore, when we evaluate the patient's condition and make a treatment plan, it must comprehensively analyze patients' various characteristics.

So far, the pathogenesis about IPM influenza coinfection is not very clear. Based on the research of many experts, we speculate the possible pathogenesis may be related to the following factors: first, the damage of respiratory mucosa, normal ciliary clearance, and interruption of interleukin secretion caused by influenza virus infection may lead to fungal invasion; ${ }^{30,31}$ second, severe influenza may cause the imbalance of $\mathrm{T}$ cell differentiation and cell-mediated immune injury, leading to reduce the patient's immune response, ${ }^{9,21,32}$ third, the using of corticosteroids and broad-spectrum antibiotics can also cause immune damage and dysbacteriosis; ${ }^{30}$ four, inhibition of neuraminidase in host neutrophils by neuraminidase inhibitors such as oseltamivir may increase the chance of fungal infection; ${ }^{33}$ five, using of IPPV and ECMO for respiratory support significantly increased the risk of fungus involvement. ${ }^{34}$ In our study, the difference of ECMO using, corticosteroids using, and multiple antibiotics using in two groups was not statistically significant, but the level of CD4+ T cells in the IPM group was much lower than the non-IPM group. This result suggests the imbalance of
$\mathrm{T}$ cell differentiation and cell-mediated immune injury play an important role in the pathogenesis process of IPM.

Through multivariate logistic regression analysis, we found the influenza patients with older age, hypoimmunity, liver disease, hypertension, positive serum GM test, steroids using, gasping, gastrointestinal symptoms, high APECHEII, low oxygenation index, other viruses co-infection, bacterial co-infection, low lymphocyte counts, low $\mathrm{CD} 4+\mathrm{T}$ cell counts, low CD8+ T cell counts, low RBC, low hemoglobin, low platelets, high $\mathrm{N} \%$, low total protein, high CRP, low albumin, low fibrinogen, high BUN, positive serum GM test, more mechanical ventilation requirement and more renal replacement requirement have a high risk of IPM coinfection. Evaluating clinical features and examination outcomes of patients as soon as possible after admission is very critical for medication. Early diagnosis and precise treatment can greatly reduce the mortality of influenza patients.

\section{Conclusion}

Influenza associated IPM is a common and severe complication of influenza patients in the RICU and may lead to a poor outcome even in immune competent individuals. Evaluating the risk factors of influenza associated IPM infection as soon as possible, early diagnosis with multiple biomarker diagnostic strategies and early application of antifungal drugs are critical to improve prognosis. Clinicians caring for patients with severe influenza should consider IPM.

\section{Ethics and Consent}

This study was conducted according to the Declaration of Helsinki, reviewed and approved by the Ethics Committee of Beijing Chao-Yang Hospital. Written informed consent was obtained from selected patients themselves or their close legal relatives.

\section{Acknowledgments}

This work was supported by all co-workers in the respiratory intensive care unit of Beijing Chao-yang hospital.

\section{Disclosure}

The authors report no conflicts of interest in this work.

\section{References}

1. WHO. Influenza (Seasonal) Fact Sheet; 2016.

2. Akers IE, Weber R, Sax H, Böni J, Trkola A, Kuster SP. Influence of time to diagnosis of severe influenza on antibiotic use, length of stay, isolation precautions, and mortality: a retrospective study. Influenza Other Respir Viruses. 2017;11(4):337-344. doi:10.1111/irv.12454 
3. Beumer MC, Koch RM, van Beuningen D, et al. Influenza virus and factors that are associated with ICU admission, pulmonary co-infections and ICU mortality. J Crit Care. 2019;50:59-65. doi:10.1016/j.jcrc.2018.11.013

4. Kash JC, Taubenberger JK. The role of viral, host, and secondary bacterial factors in influenza pathogenesis. Am J Pathol. 2015;185 (6):1528-1536. doi:10.1016/j.ajpath.2014.08.030

5. Grimaldi D, Llitjos JF, Pène F. Post-infectious immune suppression: a new paradigm of severe infections. Med Mal Infect. 2014;44 (10):455-463. doi:10.1016/j.medmal.2014.07.017

6. Shi SJ, Li H, Liu M, et al. Mortality prediction to hospitalized patients with influenza pneumonia: $\mathrm{PO} 2 / \mathrm{FiO} 2$ combined lymphocyte count is the answer. Clin Respir J. 2017;11(3):352-360. doi:10.1111/crj.12346

7. Abbott JD, Fernando HV, Gurling K, Meade BW. Pulmonary aspergillosis following post-influenzal bronchopneumonia treated with antibiotics. $\mathrm{Br}$ Med J. 1952;1(4757):523-525. doi:10.1136/ bmj.1.4757.523

8. Crum-Cianflone NF. Invasive aspergillosis associated with severe influenza infections. Open Forum Infect Dis. 2016;3(3):ofw171. doi:10.1093/ofid/ofw171

9. Huang L, Zhang N, Huang X, et al. Invasive pulmonary aspergillosis in patients with influenza infection: a retrospective study and review of the literature. Clin Respir J. 2019;13(4):202-211. doi:10.1111/crj.12995

10. Guervilly C, Roch A, Ranque S, et al. A strategy based on galactomannan antigen detection and PCR for invasive pulmonary aspergillosis following influenza A (H1N1) pneumonia. J Infect. 2012;65 (5):470-473. doi:10.1016/j.jinf.2012.07.007

11. Waldeck F, Boroli F, Suh N, et al. Influenza-associated aspergillosis in critically-ill patients-a retrospective bicentric cohort study. Eur J Clin Microbiol Infect Dis. 2020;39(10):1915-1923. doi:10.1007/ s10096-020-03923-7

12. De Pauw B, Walsh TJ, Donnelly JP, et al. Revised definitions of invasive fungal disease from the European Organization for Research and Treatment of Cancer/Invasive Fungal Infections Cooperative Group and the National Institute of Allergy and Infectious Diseases Mycoses Study Group (EORTC/MSG) Consensus Group. Clin Infect Dis. 2008;46(12):1813-1821.

13. De Pascale G, Tumbarello M. Fungal infections in the ICU: advances in treatment and diagnosis. Curr Opin Crit Care. 2015;21 (5):421-429. doi:10.1097/MCC.0000000000000230

14. Brundage JF. Interactions between influenza and bacterial respiratory pathogens: implications for pandemic preparedness. Lancet Infect Dis. 2006;6:303-312. doi:10.1016/S1473-3099(06)70466-2

15. Clancy CJ, Nguyen MH, Kraft CS. Diagnosing invasive candidiasis. J Clin Microbiol. 2018;56(5):e01909-e01917. doi:10.1128/JCM.0190917

16. Cuenca-Estrella M, Kett DH, Wauters J. Defining standards of CARE for invasive fungal diseases in the ICU. J Antimicrob Chemother. 2019;74(Suppl2):ii9-ii15. doi:10.1093/jac/dkz038

17. Chertow DS, Memoli MJ. Bacterial coinfection in influenza: a grand rounds review. JAMA. 2013;309:275-282. doi:10.1001/jama.2012. 194139

18. Centers for Disease Control and Prevention (CDC). Bacterial coinfections in lung tissue specimens from fatal cases of 2009 pandemic influenza A (H1N1) - United States, May-August 2009. MMWR Morb Mortal Wkly Rep. 2009;58(38):1071-1074.

19. Gill JR, Sheng ZM, Ely SF, et al. Pulmonary pathologic findings of fatal 2009 pandemic influenza A/H1N1 viral infections. Arch Pathol Lab Med. 2010;134(2):235-243. doi:10.5858/134.2.235
20. Mauad T, Hajjar LA, Callegari GD, et al. Lung pathology in fatal novel human influenza A (H1N1) infection. Am J Respir Crit Care Med. 2010;181(1):72-79. doi:10.1164/rccm.200909-1420OC

21. Wauters J, Baar I, Meersseman P, et al. Invasive pulmonary aspergillosis is a frequent complication of critically ill $\mathrm{H} 1 \mathrm{~N} 1$ patients: a retrospective study. Intensive Care Med. 2012;38(11):1761-1768. doi:10.1007/s00134-012-2673-2

22. Vanderbeke L, Spriet I, Breynaert C, Rijnders BJA, Verweij PE, Wauters J. Invasive pulmonary aspergillosis complicating severe influenza: epidemiology, diagnosis and treatment. Curr Opin Infect Dis. 2018;31(6):471-480. doi:10.1097/QCO.0000000000000504

23. Fischer JJ, Walker DH. Invasive pulmonary aspergillosis associated with influenza. JAMA. 1979;241(14):1493-1494. doi:10.1001/ jama.1979.03290400053024

24. Horn CR, Wood NC, Hughes JA. Invasive aspergillosis following post-influenzal pneumonia. $\mathrm{Br} J$ Dis Chest. 1983;77(4):407-410. doi:10.1016/0007-0971(83)90078-5

25. Alshabani K, Haq A, Miyakawa R, Palla M, Soubani AO. Invasive pulmonary aspergillosis in patients with influenza infection: report of two cases and systematic review of the literature. Expert Rev Respir Med. 2015;9(1):89-96. doi:10.1586/17476348.2015.996132

26. Althoff Souza C, Müller NL, Marchiori E, Escuissato DL, Franquet T. Pulmonary invasive aspergillosis and candidiasis in immunocompromised patients: a comparative study of the high-resolution CT findings. $J$ Thorac Imaging. 2006;21 (3):184-189. doi:10.1097/01.rti.0000213552.16011.ad

27. Chen KY, Ko SC, Hsueh PR, Luh KT, Yang PC. Pulmonary fungal infection: emphasis on microbiological spectra, patient outcome, and prognostic factors. Chest. 2001;120(1):177-184. doi:10.1378/ chest.120.1.177

28. Pound MW, Drew RH, Perfect JR. Recent advances in the epidemiology, prevention, diagnosis, and treatment of fungal pneumonia. Curr Opin Infect Dis. 2002;15(2):183-194. doi:10.1097/00001432200204000-00014

29. Kosmidis C, Denning DW. The clinical spectrum of pulmonary aspergillosis. Thorax. 2015;70:270-277. doi:10.1136/thoraxjnl2014-206291

30. Schauwvlieghe A, Rijnders BJA, Philips N, et al. Invasive aspergillosis in patients admitted to the intensive care unit with severe influenza: a retrospective cohort study. Lancet Respir Med. 2018;6 (10):782-792. doi:10.1016/S2213-2600(18)30274-1

31. Garcia-Vidal C, Barba P, Arnan M, et al. Invasive aspergillosis complicating pandemic influenza A (H1N1) infection in severely immunocompromised patients. Clin Infect Dis. 2011;53(6):e16-e19. doi:10.1093/cid/cir485

32. Adalja AA, Sappington PL, Harris SP, et al. Isolation of aspergillus in three $2009 \mathrm{H} 1 \mathrm{~N} 1$ influenza patients. Influenza Other Respir Viruses. 2011;5(4):225-229. doi:10.1111/j.1750-2659.20 11.00202.x

33. Veerdonk F, Dewi I, Cunha C, et al. Inhibition of host neuraminidase increases susceptibility to invasive pulmonary aspergillosis. Open Forum Infect Dis. 2018;5(suppl 1):S36. doi:10.1093/ofid/ ofy 209.083

34. Peek GJ, Mugford M, Tiruvoipati R, et al. Efficacy and economic assessment of conventional ventilatory support versus extracorporeal membrane oxygenation for severe adult respiratory failure (CESAR): a multicentre randomised controlled trial [published correction appears in Lancet. Lancet. 2009;374(96 98):1351-1363. 


\section{Publish your work in this journal}

The International Journal of General Medicine is an international, peer-reviewed open-access journal that focuses on general and internal medicine, pathogenesis, epidemiology, diagnosis, monitoring and treatment protocols. The journal is characterized by the rapid reporting of reviews, original research and clinical studies across all disease areas. The manuscript management system is completely online and includes a very quick and fair peer-review system, which is all easy to use. Visit http://www.dovepress.com/ testimonials.php to read real quotes from published authors. 